\title{
RELAÇÕES ENTRE O ESTADO E A ESCOLA NO BRASIL, PARTICIPAÇÃO E POLÍTICAS EDUCACIONAIS E O PLANO DA EFETIVIDADE, A POSSIBILIDADE E A NECESSIDADE DE GESTÃO DEMOCRÁTICA
}

\author{
Paulo Gomes LIMA ${ }^{1}$ \\ Maria Alice de Miranda ARANDA ${ }^{2}$ \\ Antonio Bosco de LIMA ${ }^{3}$
}

RESUMO: Estudo sobre as relações entre Estado e escola no Brasil, o âmbito da participação nas políticas educacionais e a gestão democrática em três eixos: efetividade, possibilidade e necessidade. Por meio do materialismo histórico dialético destacamos que a educação veiculada em todo o mundo como direito de todo homem e como passaporte para a sua riqueza a partir da década de 1990, ascendeu como especial atenção em meio ao modo-de-produção capitalista, como alternativa unilinear de solidarização econômica, social e política, de modo particular nas políticas educacionais do Brasil, inicialmente no governo de Fernando Henrique Cardoso e tendo continuidade no governo petista de Luís Inácio Lula da Silva por meio de suas projeções de participação popular anunciadas e listadas Plano Plurianual (PPA) 2004-2007, consistindo numa gestão democrática consentida. Este movimento de esvaziamento do político, com conseqüente fortalecimento de resultados pragmáticos, a exemplo do mercado, mudou a o foco da centralidade do poder decisório, do coletivo para o autocrático e também o reducionismo dos movimentos populares e sociais, instituindo na escola canais legítimos de participação (conselhos, associações de pais e mestres, constituinte escolar, dentre outros) ritmados pelo ideário da reprodução capitalista.

PALAVRAS-CHAVE: Estado. Escola. Participação. Políticas educacionais. Gestão democrática.

\section{Introdução}

A adoção das macropolíticas neoliberais no Brasil implicou e ainda implica o desmonte de instrumentos da soberania nacional e dos direitos fundamentais do cidadão, pelo sufocamento das aspirações de emancipação social, em nome do crescimento econômico e erradicação da pobreza, contraditoriamente, de forma solidária com a lógica dissimulada do capital, tornando-se, no caso, o referencial das políticas públicas para a educação sob a tutela da solidariedade capitalista.

\footnotetext{
${ }^{1}$ Docente do PPGED. UFSCAR - Universidade Federal de São Carlos. São Carlos - SP - Brasil. 18052780 - paulolima@ufscar.br

${ }^{2}$ Docente da UFGD. UFGD - Universidade Federal da Grande Dourados. Dourados - MS - Brasil. 79.825070 - mariaaranda@ufgd.edu.br

${ }^{3}$ Docente da UFU. UFU - Universidade Federal de Uberlândia. Uberlândisa - MG - Brasil. 38408-100 boscodelima@gmail.com
} 
A ordenação da reestruturação produtiva irá conduzir as políticas públicas do Brasil a partir da década de 1990, afinando o ideário capitalista tanto na conformação do Estado, quanto na indução de políticas educacionais que concorreriam para àquela finalidade. Este quadro contribuiria para o consentimento da participação popular nas escolas, mediante canais legítimos de maneira meramente representativa, alienando qualquer perspectiva de engajamento político e construção de consciência coletiva.

Recortando-se a lógica do Plano Plurianual (PPA) 2004-2007, documento que legalmente norteou a primeira gestão governamental (2003-2006) de Luiz Inácio Lula da Silva, destacamos que os indícios da participação declarada no Programa Nacional de Fortalecimento dos Conselhos Escolares, especificamente no Caderno Introdutório do Programa, traz implícita a concepção neoliberal de democracia buscando apenas incrementar a participação instrumental via Conselhos e elaboração de Propostas Pedagógicas. Portanto, tem-se a participação como ponto de convergência na gestão da política educacional dos anos iniciais do século XXI fazendo a relação Estado e Sociedade, apenas como um meio que aspira ao bem-estar de todos na sociedade capitalista, demarcando considerável distância em direção a um projeto de sociedade que conceba a todos os homens o status de sujeito da história.

Consequentemente o modelo de gestão vigente não contempla a perspectiva de gestão democrática (GD) (participação, descentralização, autonomia e poder local), mas um postulado de gestão compartilhada, a qual se sustenta pela hierarquização, pela participação tutelada, pelo controle verticalizado das decisões e pela auto-manutenção da escola. Desta forma entendemos que o postulado de gestão democrática oficializado nas políticas educacionais e implementado pelos sujeitos que compõem os vários segmentos da escola não corresponde ao modelo idealizado e desenhado na década de 80 , quando os elementos que instituíam a GD congregavam práticas transformadoras e participativas como a socialização do poder, a transparência de informações, o poder de decisão colegiado, implementados por via de conselhos, eleições de diretores, planejamento participativo. Embora a partir da segunda metade dos anos de 1990 tenhamos tais elementos em "pleno" funcionamento, já não atuam na estruturação do poder decisório (aspecto político), mas na condução de uma organização eficiente (aparato técnicoburocrático).

Este movimento do esvaziamento do político, com consequente fortalecimento do pragmático mudou a o foco da centralidade do poder decisório, do coletivo para o autocrático, efetuando assim, uma mudança na esfera de controle social, antes construção 
por parte da sociedade civil organizada, agora focaliza-se no controle que o Estado vai construindo sobre a sociedade civil organizada, esvaziando os movimentos populares e os movimentos sociais, instituindo na escola aparatos de representatividade em instituições escolares, os intitulados canais legítimos de participação (conselhos, associações de pais e mestres, constituinte escolar, dentre outros), assim este estudo poderá contribuir para problematizarmos as relações entre Estado e escola no Brasil, o âmbito da participação nas políticas educacionais e a gestão democrática em três eixos: efetividade, possibilidade e necessidade.

\section{Estado e escola no Brasil}

As formas de regulação transnacional de mercado ao final da década de 1980 impulsionaram um quadro de reorganização da lógica capitalista na perspectiva de mudança reestruturativa da produção, do papel do Estado, enquanto agente regulador e dos meios para a naturalização de seus pressupostos, dentre os quais a educação e o combate à miséria eram comumente o foco.

Em 1994, ainda como candidato, Fernando Henrique Cardoso afirmava que o cerne de seu mandato seria a garantia de condições dignas de vida para o mais humilde cidadão e que promoveria o desenvolvimento do país com justiça social, crescimento com melhores salários, progresso com carteira assinada, saúde e crianças na escola e isto atrelado a interface da C\&T, como se vê defendido de forma transversal no "Programa Mãos à obra, Brasil” (LIMA, 2005). E neste esforço colocava como prioridade dar estabilidade e condições de bom funcionamento aos principais centros de excelência do país, tornar os mestrados mais eficientes e voltados para o mercado de trabalho e a diminuição do tempo e melhoria da qualidade dos doutores brasileiros. É interessante que o seu programa trazia a proposta da privatização como elemento saneador da falta de recursos e propunha encaminhamentos para esta área por meio de empréstimos e entradas externas, o que de fato viria a acontecer no Brasil, a um preço nunca visto antes.

Lima (2009a) enfatiza que significativos impactos de agências multilaterais às políticas educacionais no Brasil foram deflagrados com maior ênfase em meio à promoção da reestruturação produtiva e reforma do Estado a partir da década de 1990. A presença do Estado brasileiro, a partir da referida década, como agente regulador da economia, atendeu aos rogos do mercado internacional com forte ênfase na introdução e desenvolvimento de novos padrões da força produtiva e da adequação da força de trabalho. A orientação neoliberal de uma reestruturação produtiva, neste sentido, 
solicitava a reforma do Estado, projetando, consequentemente a tipologia necessária de “cidadão globalizado para a "inclusão social brasileira" das "benfeitorias da relação capital-trabalho" enfaticamente valorizada pelos países centrais por meio de suas ideologias em sentido restrito.

A escola no Brasil, marcada por arranjos históricos de exclusão voltada ao controle social por meio do poder político e para a formação de elites pertinentes desde sua inauguração deveria ser "trabalhada" para os novos tempos - tempos de reversão das injustiças sociais, tempos de correção de dívidas históricas em nome do "crescimento econômico e social das nações". Como agente fomentador e catalisador das manifestações econômicas, políticas e ideológicas na proposição de uma "falseada consciência do real", o Estado brasileiro não logrou resistências para a reforma da escola, uma vez que sob o discurso da social-democracia propunha a elevação da oferta, acesso, gratuidade e qualidade educacional pela orientação de uma "revolução educacional gerenciada".

O espaço "outorgado" às vozes das classes desfavorecidas como preocupação do capital, fora objeto do ideário neoliberal na expansão de mercado por meio da elevação simbólica do poder aquisitivo dos cidadãos nos anos de 1990 (avançando consideravelmente nos primeiros anos do século XXI), "educando-os" para a permanência da aceitação tácita centrada na policompetência da divisão social do trabalho, de forma especial nos países de economias emergentes no cenário mundial, como o caso do Brasil, enquanto que aqueles países notadamente mais periféricos e pobres eram assistidos por auxílios diversos na orientação de suas políticas sociais, dentre as quais para a alimentação, saúde e educação, de forma controlada, apresentando visibilidade suficiente para a atestação do "papel de responsabilização do capital no atendimento às necessidades dos que sofrem" (LIMA, 2009b) qualquer tipo de privação no mundo dos homens, ratificando ideologicamente a necessidade de sua teoria social.

A escola no Brasil condicionada por um Estado neoliberal inculcava a necessidade de uma postura reflexiva por parte dos professores, pais e comunidade quanto à luta contra a exclusão, com o comprometimento de uma educação de qualidade para todos, contra a violência, a favor da construção crítica da cidadania. Tais pontuações, entretanto, tangenciavam as intencionalidades da exploração do capital e a adesão e adequação brasileira de sua escola à esse processo dissimulado e metamorfoseado de solidariedade. O papel político da educação escolar com o passar do tempo, levando em conta a relação da acumulação do capital, produz e reforça a hegemonia de classes sociais com a ênfase 
na expansão de educação básica para o povo e sua preparação para um mercado de trabalho determinado e, ao mesmo tempo, promove a contenção das medidas estruturais para a educação superior daquelas, na medida em que confere ao âmbito meritocrático o acesso e ingresso à universidade pública, por seu caráter de atendimento elitista.

\section{A participação na política educacional}

Segundo registros no texto do PPA (Plano Plurianual) 2004-2007 "Brasil de Todos: inclusão e participação", a proposição é concretizar uma política educacional que tenha em sua base a participação de todos os brasileiros, denominados no documento de cidadãos. Está registrado que "o caminho para um projeto de futuro para o Brasil começa pela educação". (BRASIL, 2003, p.16).

Assim, a gestão pública participativa na educação vem fazendo parte do rol de orientações planejadas pelas instituições sociais coordenadas pelo poder central que implanta e/ou implementa programas, decide quais instrumentos serão viáveis para a população escolar participara das decisões. Tais instrumentos são os conselhos, os fóruns de representação e de debates com a proposição de reunir diversos segmentos da sociedade civil, com o objetivo de consolidar o sistema de participação social proposto pelo Governo Federal, conforme orientações registradas no PPA 2004-2007 "Brasil de Todos: inclusão e participação".

Nessa direção, os programas "Democratização da Gestão nos Sistemas de Ensino" e "Gestão da Política de Educação" foram criados com o objetivo de promover e de fortalecer esse sistema de participação na gestão educacional pública. Focando em especial para o "Programa Gestão da Política de Educação" foi possível constatar que o mesmo vem sendo materializado pelo "Programa Nacional de Fortalecimento dos Conselhos Escolares" (BRASIL, 2004a), diretamente voltado para as Secretarias de Educação e suas Unidades Escolares de Educação Básica.

O Programa Nacional de Fortalecimento dos Conselhos Escolares tem como objetivo promover e fortalecer a gestão democrática nos estados e municípios, assegurando a implementação de forma contínua e eficaz da política educacional, buscando legitimar mecanismos de participação e de controle social, por meio de organizações colegiadas; logo, selecionado para aprofundar a compreensão de como está sendo proposto o princípio da participação na educação com vistas a orientar a política educacional e assegurar o resgate à cidadania. 
Dados da Secretaria de Educação Básica (SEB/MEC) apontam a existência de mais de 60 mil conselhos em escolas públicas do País. Formados por professores, funcionários, pais, alunos, diretores e comunidade local. Eles têm funções deliberativas, consultivas, fiscais e de mobilização e são co-responsáveis pela gestão administrativa, financeira e pedagógica da escola. Foi elaborado com a participação de organismos nacionais e internacionais em um Grupo de Trabalho constituído para discutir, analisar e propor medidas para sua implementação. As entidades participantes foram as que seguem: Conselho Nacional de Secretários de Educação (CONSED); União Nacional dos Dirigentes Municipais de Educação (UNDIME); Confederação Nacional dos Trabalhadores em Educação (CNTE); Fundo das Nações Unidas para a Infância (UNICEF); Organização das Nações Unidas para a Educação, a Ciência e a Cultura (UNESCO); e o Programa das Nações Unidas para o Desenvolvimento (PNUD).

Com essa sustentação, a Secretaria de Educação Básica do Ministério da Educação, por meio da Coordenação-Geral de Articulação e Fortalecimento Institucional dos Sistemas de Ensino, do Departamento de Articulação e Desenvolvimento dos Sistemas de Ensino, vem desenvolvendo ações no sentido de implementar o Programa Nacional de Fortalecimento dos Conselhos Escolares.

Assim, objetivando firmar uma determinada concepção de participação que se diz popular, o MEC lançou o kit formado por um caderno introdutório e instrucional denominado "Conselhos Escolares: uma Estratégia de Gestão Democrática da Educação Pública" que é destinado aos dirigentes e técnicos das secretarias municipais e estaduais de educação e mais dez cadernos também instrucionais destinados aos conselheiros escolares. $\mathrm{O}$ material (kit) foi distribuído às escolas públicas com mais de 250 alunos. $\mathrm{O}$ Kit demonstra o desenvolvimento do Programa em todas as suas etapas, visando assegurar a relação do governo e do MEC em regime de colaboração com os sistemas de ensino, em específico com as escolas públicas de educação básica, de modo a fortalecer a política educacional no fomento à implantação de um instrumento básico de participação: os Conselhos Escolares.

Considerou-se nesse estudo a efetivação de uma análise apenas no Caderno Introdutório, uma vez que o mesmo responde ao buscado no estudo. É um documento organizado de forma clara e rica de informação e formação. Além de apresentar todo o Programa oferece subsídios teóricos e práticos aos dirigentes e técnicos das secretarias estaduais e municipais de educação e também aos gestores escolares com base em uma reflexão sobre a importância da ação colegiada, da gestão democrática da educação 
pública, bem como pontos da legislação municipal e estadual referentes aos Conselhos Escolares.

O objetivo geral registrado no Caderno Introdutório é oferecer subsídios teóricos e práticos para a compreensão do significado dos conselhos na gestão da educação pública, destacando o seu papel na concretização forma de cidadania anunciada e colocando-o como "[...] um importante passo para garantir a efetiva participação das comunidades escolar e local na gestão das escolas, contribuindo, assim, para a melhoria da qualidade social da educação ofertada para todos". (BRASIL, 2004b, p.11).

E são destaques também os seguintes objetivos específicos:

[...] oferecer uma fundamentação teórica sobre os conselhos na gestão da educação, origens e bases históricas, mostrando a evolução de sua concepção ao longo do tempo; mostrar as diferenças entre conselhos de sistemas de educação e conselho de escolas; distinguir a natureza própria dos Conselhos Escolares e das instituições complementares à escola, como associações de pais e mestres, caixa escolar e outros mecanismos de apoio à gestão da escola; refletir sobre o significado do princípio constitucional da gestão democrática da educação pública. (BRASIL, 2004, p.14-15).

Registra o documento que com esses objetivos ficam explícitos “[...] os diferentes conceitos e naturezas das diferentes formas de colegiados na gestão da educação no Brasil, tanto no âmbito dos sistemas de ensino, quanto das instituições educacionais". (BRASIL, 2004, p.15). E que legalmente fica atendido o princípio constitucional da gestão democrática da educação pública, assegurado na Constituição Federal de 1988, ao destacar que "[...] a nova institucionalidade dos Conselhos Escolares apresenta-se como uma estratégia central nessa busca". (BRASIL, 2004, p.15).

O documento apresenta na primeira parte uma contextualização histórica dos conselhos nos processos de gestão dos sistemas e das instituições de ensino com o objetivo de oferecer algumas reflexões conceituais e informações sobre as experiências em curso nos sistemas de ensino, com vistas a servir de orientação para os gestores na implantação e na dinamização dos mesmos.

Continua nos registros a afirmação que na primeira metade do século $\mathrm{XX}$ o exercício da democracia direta e da democracia representativa é estratégia para resolver as tensões e conflitos resultantes dos diferentes interesses entre o Estado e a sociedade. Nesses termos, os conselhos se situam na interface entre o Estado e a sociedade, “[...] ora na defesa dos interesses das elites, tutelando a sociedade, ora, e de maneira mais incisiva 
nos tempos atuais, buscando a co-gestão das políticas públicas e se constituindo canais de participação popular na realização do interesse público”. (BRASIL, 2004b, p.18).

A justificativa para a afirmação feita é que no Brasil, como o advento da República (Res publica), a gestão da coisa pública é marcada por uma concepção patrimonialista de Estado, este pertencente a uma determinada autoridade que se institui por uma burocracia baseada na obediência à vontade superior. Registra o documento que até hoje os conselhos são, no geral, constituídos por notáveis, pessoas dotadas de saber erudito, letrados, pessoas que demonstram certo grau de liderança, o que já demonstra um significado de participação.

Outro ponto interessante colocado no documento é quanto ao papel dos conselhos em relação ao governo. Tendo como atribuições assessorá-lo na formulação de políticas públicas, esses conselhos se assumiam como de caráter técnico especializado, e sua atuação se concentrava nas questões da normatização e do credencialismo dos respectivos sistemas.

E mais recentemente, no processo de democratização ocorrido nas décadas anteriores a 1990 e nos anos posteriores, há ainda o reclamo pela participação efetiva na gestão pública, impondo a necessidade de ampliação dos mecanismos de gestão das políticas públicas. Assim, vêm sendo criadas políticas setoriais, com definição discutida em conselhos próprios, com abrangências variadas: unidades da federação, programas de governo, redes associativas populares, movimentos sociais específicos e categorias institucionais.

Os conselhos de gestão de políticas públicas setoriais, caracterizados simples e essencialmente como conselhos da cidadania, sociais ou populares, nascem das categorias associadas de pertencimento e participação e se tornam a expressão de uma nova institucionalidade cidadã. A nova categoria de participação cidadã tem como eixo a construção de um projeto de sociedade, que concebe o Estado como um patrimônio comum a serviço dos cidadãos, sujeitos portadores de poder e de direitos relativos à comum qualidade de vida. Os conselhos representam hoje uma estratégia privilegiada de democratização das ações do Estado (BRASIL, 2004b).

Nesse sentido, o processo de gestão democrática da coisa pública, consignada pela Constituição Federal de 1988, que sugere a atuação dos Conselhos como instrumento da gestão democrática, passa a situar o espaço dos Conselhos com dimensão de órgãos de Estado, de modo a assumir uma nova institucionalidade e ao contrário do que anuncia pode vir a descaracterizar a expressão da sociedade organizada. 
Fica, portanto, vaga a afirmação que não se está atribuindo aos Conselhos as “[...] responsabilidades de governo, mas de voz plural da sociedade para situar a ação do Estado na lógica da cidadania". (BRASIL, 2004b, p.20). O que fica claro é que "[...] os conselhos representam hoje uma estratégia privilegiada de democratização das ações do Estado" (BRASIL, 2004b, p.19), que não é o Estado amplo no sentido gramsciano.

Os princípios destacados como fundamentais para o funcionamento de um conselho em defesa dos direitos educacionais da cidadania como "[...] o caráter público, a voz plural representativa da comunidade, a deliberação coletiva, a defesa dos interesses da cidadania e o sentido do pertencimento" (BRASIL, 2004b, p.23), precisam ser olhados pela concepção de democracia capaz de sustentá-los.

O mesmo se pode afirmar quanto à inserção dos Conselhos na estrutura dos sistemas de ensino como mecanismos de gestão colegiada. Este termo está sendo usado genericamente para caracterizar a ação dos conselhos, mas assume especificidade própria nas instituições de ensino para tornar presente a expressão da vontade da sociedade na formulação das políticas e das normas educacionais e nas decisões dos dirigentes.

Por isso, afirma-se que o Conselho Escolar, do modo como vem sendo encaminhado pelo Estado tem sim, o duplo desafio em destaque: “[...] primeiro, garantir a permanência da institucionalidade e da continuidade das políticas educacionais; e, segundo, agir como instituintes das vontades da sociedade que representam" (BRASIL, 2004b, p.24), certamente da sociedade capitalista.

O Conselho Escolar foi instituído com excessivo detalhamento a partir de fora, tornando questionável a participação, limitando o espaço de exercício da autonomia da escola, no sentido da criação da própria norma, e ademais, o forte sentido de pertencimento remete a fazer e viver a sociedade e a escola que aí está no papel de cidadão, que, segundo registros no documento dá a característica necessária ao “[...] elemento mais poderoso de criação, renovação e formação de sujeitos autônomos e solidários: cidadãos”. (BRASIL, 2004b, p.58-59).

O que se pode aferir é que essa forma de participação delineada no Caderno Introdutório do Programa de Fortalecimento dos Conselhos Escolares, ao ser entendida como possível de ser radicada no coletivo, oportunizando ao cidadão se tornar amplo, isento da exclusão social e se situar como governante do processo social, precisa passar por um processo reflexivo quanto a aprofundar a compreensão da natureza da estrutura do sistema-capital que não chega a negar no espaço educacional do capitalismo uma mobilização e engajamento para a participação nas formulações e implementação de suas 
políticas, mas a delimita quanto às possibilidades mais amplas que poderiam superar tal sistema nas distintas perspectivas de gestão democrática, como analisaremos a seguir.

\section{O plano da efetividade, a possibilidade e a necessidade de gestão democrática}

Partimos de três postulados como forma de problematização da gestão democrática da escola pública no Brasil, o que nos possibilitará a análise do âmbito de sua consecução ou não nos arranjos das políticas educacionais na contemporaneidade.

Primeiro postulado: a idéia é tratar a análise da gestão democrática a partir daquilo que foi preconizado/idealizado como gestão democrática (tese), aquilo que temos, ou seja, o que tem sido a gestão (antítese), e, a partir destes elementos, compor algumas idéias de um vir a ser, aquilo que entendemos e queremos com a gestão democrática (síntese).

Segundo postulado: a gestão democrática, como a democracia, é um processo, e como tal não é produto acabado. E, por estar em constante construção, oscila entre as possibilidades participativas e os limites centralizadores.

Terceiro postulado: existem três elementos básicos para a construção da gestão democrática: a descentralização, a autonomia e a participação. Sendo que a descentralização contempla os preceitos da autonomia e da participação. Um processo de descentralização articula o poder político de projetar e planejar de forma autônoma e participativa o ente descentralizado, aquilo que conhecemos como poder local. Não existe, portanto descentralização sem autonomia e sem participação. Tampouco gestão democrática.

A síntese: destes três postulados podemos fazer uma síntese: a gestão democrática só é possível quando o poder está descentralizado, e, é claro, existem sujeitos participativos no processo, que ao atuarem no processo decisório contribuem para consolidar o movimento histórico necessário para tornar as instituições democráticas e, assim, fazer a democracia avançar.

Chegamos, então a uma síntese, que, como vimos, destaca os princípios participativos como objeto e objetivo central de qualquer relação que se proponha a ser democrática. Daí chegamos a um elemento fundamental, que subsidia tanto as pesquisas quanto as ações dos sujeitos, a problematização. Tomamos a participação como base e princípio do processo democrático. A problematização da questão da participação como postulado da democratização nos leva a três planos, que discutimos a seguir.

\section{O plano da efetividade de gestão democrática}


A efetividade da gestão democrática está ligada a sua infalibilidade. A idéia de infalibilidade como eixo central para a democratização cai em dois erros: o primeiro é de supor que no capitalismo teremos uma democracia plena, afinal o capitalismo não casa com a democracia, pois é um noivo que exclui ao invés de incluir, que institui um falso consenso, que se alimenta da miséria para ser portentoso, enquanto a democracia é uma noiva irregular, conflitual, que não admite desigualdades, que busca incluir universalmente.

O segundo erro é acreditar que no capitalismo igualdade pode ser compartilhada com liberdade. No capitalismo a igualdade é abafada pela liberdade. A igualdade no capitalismo tem suas possibilidades a partir da liberdade, que é uma moça valorada, transformada em mercadoria, adquirida a partir do poder de compra dos indivíduos individualizados. É neste sentido que destacamos a intencionalidade que se faz presente nas discussões sobre a democracia e a gestão democrática. Enquanto projetos do capital, seu concreto realizado, aquilo que vivenciamos e sabemos dos problemas.

De outra forma, a democracia e a gestão democrática é construção da classe trabalhadora. Realizada sem idealização, somente ganha uma dimensão de projeto social e amplo se tiver como base o compromisso de todos. O que significa que a democracia não pode estar na cabeça de alguns, tampouco ser obra de uns poucos, mas um projeto de vida coletivo. Daí a necessidade de entender a gestão democrática como um ir e vir. Como processo e como construção coletiva. A sua efetividade então está pautada nas mobilizações. Nas lutas conjuntas, na sociedade organizada. Ela não pode ser reduzida a canais legítimos de participação: o Conselho de Escola (CE), as Eleições de Diretores (ED), as Associações de Pais e Mestres (APMs) e o Projeto Político-Pedagógico (PPP).

Pensar que a gestão democrática é obra de lideranças bem intencionadas é acreditar em uma forma autocrática de democracia, na qual seus postulados estão hierarquizados, padronizados, organizados e dirigidos. A gestão democrática inclui, em si, postulados conflituais. Ou seja, a gestão democrática não pode ser reduzida a uma dimensão instituída, ela é sempre instituinte e instituída.

Decorre daí os seus princípios: descentralização, participação e autonomia. Tais princípios são basilares para a concretização da democratização, o que indica, uma relação de poder, a socialização do poder, a participação no poder. Descentralização só se realiza pelos elementos instituintes e instituídos: participação e autonomia. Recorremos ao pressuposto que só se efetiva aquilo que é possível, o que nos leva a um outro plano. 


\section{O plano da possibilidade de gestão democrática}

Enquanto campo da possibilidade, a gestão democrática só se configura se articulada a partir do modelo democrático-participativo, o que significa superar a perspectiva meramente representativa que as eleições, os colegiados e a demais formas de manifestação e organização foram ganhando nos últimos anos.

Isto requer, por um lado, a necessidade do compromisso político dos gestores e, por outro, do compromisso de cada membro da organização, o que significa, ter estabelecido, sistematizado e condensado quatro quesitos básicos para a implementação da gestão democrática: gostar de participar, querer participar, ter conhecimento do objeto de participação e se reconhecer neste objeto, ter o poder de participação nas tomadas de decisão. Estas são idéias de níveis de participação tomadas de Bordenave (1992).

Estes quesitos estão articulados, afinal, se o sujeito gosta, mas não quer, ou se quer, mas não pode devido aos seus horários serem incompatíveis aos horários de reunião da escola. Se ele gosta, quer e vai participar, mas não tem conhecimento do que é discutido, e finalmente se ele gosta, quer, conhece, mas não decide, não se contempla a participação. Percebemos que estes quesitos são organicamente articulados e indissociáveis.

Também são coesos os planos da efetividade e da possibilidade, orientam-se na direção de concretude quando os sujeitos têm a necessidade posta. As necessidades surgem de questões objetivas, quanto mais realizo, mais necessidades crio, quanto mais conheço mais opções tenho para análise das necessidades postas. Só é possível, então de se efetuar aquilo que consideramos como necessidade.

\section{O Plano das necessidades da gestão democrática}

A gestão democrática, a partir da efetivação de uma participação transformadora, passa por questões subjetivas e objetivas em suas duas dimensões: pela dimensão do plano real e pelo plano das necessidades de cada um e, pela dimensão do campo da formação e do campo de trabalho.

Para a apreensão do plano real basta analisar os avanços e conquistas políticas e sociais que a participação tem resultado. Na escola os responsáveis por alunos sentem-se co-participantes na tomada de decisões? Tem contribuído para que a organização da escola se aproxime de questões sociais e culturais que afetam o bairro? Tem sido melhor 
a qualidade da escola pública? Enfim, há paulatino rompimento da rigidez hierárquica da escola, no que diz respeito ao centralismo das decisões?

No que diz respeito ao plano das necessidades, são levadas em conta as necessidades da comunidade e dos alunos, ou as demandas de necessidades são constituídas do exterior, ou seja, dos órgãos centrais para as escolas e alunos?

A partir da compreensão dos campos da efetividade, da possibilidade e da necessidade de gestão democrática podemos destacar, por meio da tese da Curvatura da Vara, que Saviani (1983) toma emprestada de Lênin, a necessidade de empreendermos um processo de ressignificação da gestão democrática. Diz Saviani (1983, p.63) que:

[...] assim como para se endireitar uma vara que se encontra torta não basta colocá-la na posição correta, mas, é necessário curvá-la do lado oposto, assim também, no embate ideológico não basta anunciar a concepção correta para que os desvios sejam corrigidos; é necessário abalar as certezas, desautorizar o senso comum. E para isso nada melhor do que demonstrar a falsidade daquilo que é tido como obviamente verdadeiro demonstrando ao mesmo tempo a verdade daquilo que é tido como obviamente falso.

A partir desta idéia ou temos uma vara teimosa ou não curvarmos a vara o suficiente para que ela tomasse prumo. Ela, a vara, continua colada ao setor da hierarquização verticalizada. Pois a democratização ainda depende basicamente da vontade daqueles que estão no Staff, no poder. Não há, portanto, um modelo participativo que consiga deslocar a gestão democrática do eixo da centralização para o eixo do coletivo.

\section{Considerações finais}

Tanto no governo FHC, quanto no governo Lula fora planificada a acomodação das políticas de desenvolvimento nacional ao sistema capitalista constituído, agregandose, a partir de seus condicionantes, os elementos orientadores para resolução dos problemas sociais por meio de políticas educacionais de inclusão social, passando a constar como ponto presencial recorrente, principalmente na gestão Lula. Percebemos que havia o condicionamento do papel do Estado pela iniciativa privada e os organismos multilaterais na defesa e consecução de políticas educacionais que limitavam as mudanças necessárias para uma escola não-excludente no Brasil.

Marx (1875), na "Crítica ao Programa de Gotha", já tecia observações contundentes quanto ao caráter educador que o capital imprime ao Estado, retomando que 
a função do mesmo quanto à educação do povo deve ser no sentido de promover as possibilidades materiais para que, remetendo aos dias de hoje, a política educacional possa ser pensada pelos sujeitos do processo educacional. Reafirma-se que o ideal mesmo seria, de fato, "[...] subtrair a escola a toda influência por parte do governo [...] é o Estado quem necessita de receber do povo uma educação muito severa”. (MARX, 1875, p.223).

Dessa forma, o modo como a sociedade e também o Estado participa nas ações de elaboração, de execução, de implementação e de focalização de suas políticas públicas ou políticas sociais, em uma determinada sociedade e em um determinado período histórico, mostra a concepção de sociedade que sustenta essa participação ou vice versa. Concepção essa perceptível nos programas, nos projetos, enfim, nas ações governamentais voltadas a setores específicos, no caso deste estudo, à educação, ou seja, à política educacional. Logo, a própria definição e operacionalização de gestão democrática necessita ser problematizada, uma vez que ela não se dá unicamente pela boa vontade do gestor educacional, antes é fruto de uma conjuntura macrossocial.

Gestão democrática não é nada daquilo que pressupõe uma idealização progressiva de autonomia e poder decisório. O que temos concretamente não tem sido uma prática emancipatória, mas uma centralização de decisões substantivas, enquanto o supérfluo fica para ser "decidido" pelo que aprendemos a chamar de comunidade escolar. Esta nomenclatura, outro equivoco, pois os pais, responsáveis por alunos, alunos, professores, supervisores, orientadores, inspetores escolar, diretores, vice-diretores, bedéis, cozinheiras, serventes, e outros mais, não têm identidade coletiva, tem necessidades diferencias, portanto, não formam uma comunidade, formam grupos distintos, que se organizam num mínimo necessário para sobreviver na organização escolar. É necessário uma outra curvatura da vara.

Curvar a vara significa resgatar os princípios da democratização, da participação e da autonomia. Tais princípios, hoje submetidos à lógica de mercado, individualizam os sujeitos, impingindo-lhes competências de adequação e adaptação aos processos de exclusão social, o que significa que a responsabilidade sobre o sucesso ou fracasso de cada um será obra de cada um. Não! Não podemos conviver com esta harmonia. É preciso estabelecer o pacto coletivo, de escolhas coletivas, onde cada um de nós é sujeito da história, e responsável por ela. 


\section{RELATIONS BETWEEN THE STATE AND THE SCHOOL IN BRAZIL, PARTICIPATION AND EDUCATIONAL POLICIES AND THE TERMS OF EFFECTIVENESS, THE POSSIBILITY AND THE NECESSITY OF DEMOCRATIC ADMINISTRATION}

ABSTRACT: Study on the relationship between the State and the school in Brazil, the scope of participation in educational policies and democratic management in three areas: effectiveness, possibility and necessity. By means of historical materialism dialectic we highlight that education provided throughout the world as the right of every man and as a passport to their wealth from the early 1990, ascended as special attention amid the mode-of-capitalist production as an alternative to unilateral economic, social and political solidarização, especially in the educational policies of Brazil, initially in the Government of Fernando Henrique Cardoso and having continuity in PT Government of Luís Inácio Lula da Silva through their projections of popular participation announced and listed pluriannual plan (PPA) 2004-2007, consisting in a democratic administration consented.This movement of emptying of the politician, with consequent strengthening of pragmatic results, market, changed the focus of the centrality of collective decisionmaking power to the autocratic and also the popular movements and social reductionism, instituting legitimate channels of participation in school (advice, parent-teacher associations, school, and other constituent) reflected by the ideals of capitalist reproduction.

KEYWORDS: Condition. School. participation. Educational policies. Democratic management.

\section{REFERÊNCIAS}

BORDENAVE, J. D. O que é participação. 7. ed. São Paulo: Brasiliense, 1992.

BRASIL. Plano Plurianual "Brasil de todos: inclusão e participação" (2004-2007). Ministério do Planejamento. Brasília: Ministério Público, 2003. Disponível em: <www.planobrasil.gov.br/arquivos. Acesso em novembro/2004>. Acesso em: 20 mai. 2013.

. Programa Nacional de Fortalecimento dos Conselhos Escolares. Instituído pela Portaria Ministerial n 2.896, de 17 de setembro de 2004. Brasília: MEC/SEB, 2004a.

Conselhos Escolares: uma estratégia de gestão democrática da educação pública. Caderno Introdutório/elaboração Genuíno Bordignon. Brasília: MEC/SEB, $2004 b$.

Constituição (1888). Constituição da República Federativa do Brasil. Brasília: Senado Federal, 1988.

LIMA, P. G. Ações afirmativas como eixo de inclusão de classes sociais menos favorecidas à universidade brasileira: um terceiro olhar entre pontos e contrapontos. 2009b. 178f. Tese (Doutorado em Educação) - Universidade Estadual de Campinas, Campinas, 2009b. 
Reestruturação produtiva, reforma do Estado e políticas educacionais no Brasil. In: Anais... Uberlândia: Universidade Federal de Minas Gerais, 2009a.

Unha de gato em novelo de lã ou do financiamento da pesquisa científica \& tecnológica no Brasil no governo Fernando Henrique Cardoso (1994-2002): o dito e o feito no "plano real". 2005. 496f. Tese (Doutorado em Educação) - Faculdade de Ciências e Letras de Araraquara, Araraquara, 2005.

MARX, K. Crítica ao Programa de Gotha. In: MARX, K.; ENGELS, F. Obras escolhidas. São Paulo: Alfa-ômega, 1875. p. 223. 3 v.

SAVIANI, D. Escola e democracia: teorias da educação, curvatura da vara, onze teses sobre educação e política. São Paulo: Cortez Autores Associados, 1983. 